\title{
Green Biosynthesis of Silver Nanoparticles Using Musa Acuminata Aqueous Flower Extract and Its Anti-Microbial Activities
}

\author{
O. Ogunmodede J. Johnson R. Osunlana S. Olarenwaju H. Ndu-Okeke \\ AfeBabalola University, Ado-Ekiti, Ekiti state, Nigeria; LadokeAkintola University of Technology, Ogbomoso, \\ Oyo state, Nigeria
}

\begin{abstract}
Nanomaterials have gained much relevant in the world of science due to their applications in catalysis, wastewater treatment and desulfurization of fossil fuels, biotechnology, pharmaceuticals and medicine. The green approach of nanoparticle synthesis employs the use of non-toxic reagents and is now preferred to the other methods which include thermal decomposition, electrochemical, photochemical, microwave assisted process chemical methods. Silver nanoparticle was biosynthesized using flower extract of Musa acuminata as reducing and capping agents. The synthesized silver nanoparticle was confirmed by the colour change after addition of the flower extract of Musa acuminata into silver nitrate solution. The silver nanoparticle was characterized by UVVisible spectrophotometer, scanning electron microscopy (SEM), energy-dispersive x-ray spectroscopy (EDX), and Fourier transform infrared (FTIR) spectrophotometer. The result of SEM reveals the formation of silver nanoparticle which was spherical in shape with varying sizes ranged between $20-30 \mathrm{~nm}$. The biosynthesized silver nanoparticle gave absorption at $375 \mathrm{~nm}$, revealed silver metal as the most abundant element, vibrational bands indicating the presence of quinone, amides and conjugated ketone which served as reducing and capping agent. The bio-synthesized silver nanoparticles revealed potent antibacterial activity and the economical synthesis of silver nanoparticle from aqueous flower extract of Musa acuminatawhich is ecofriendly.
\end{abstract}

Keywords :Green synthesis; silver nanoparticles; flower extract; capping agents; antibacterial activity; scanning electron microscopy.

DOI: $10.7176 / \mathrm{CMR} / 11-7-02$

Publication date:September $30^{\text {th }} 2019$

\section{Introduction}

Nanomaterials can be useful in such areas as catalysis [1, 2], medicine [3], waste water treatment [4-7] and desulfurization $[8,9]$. Formation of metal nanoparticles has gained enormous interest in recent times due to their exclusive characters and prospect enforcement in biotechnological stamp, pharmaceuticals, and agriculture [10, 11]. Among the nanoparticles, silver nanoparticles (AgNPs) have attracted much attention because of its attractive properties, such as a high electrical and thermal conductivity, surface-enhanced Raman scattering, chemical stability, high catalytic activity and antimicrobial activities [12-14]. There are many approaches for the synthesis of silver nanoparticles, such as thermal decomposition [15], electrochemical [16], photochemical [17], microwave assisted process [18] and green chemistry methods [19]. These methods of silver nanoparticle synthesis are either expensive or involve the utilization of hazardous chemicals. To overcome these inadequacies, developing an environmental-friendly process for silver nanoparticle synthesis using non- toxic chemicals holds the unique attention of the scientific community. Green synthesis offers a relatively safer, greener and ecofriendlier strategy for silver nanoparticle biosynthesis. Several authors have used bacteria, fungi, algae, spider cobweb and plant extracts for the green synthesis of different types of silver nanoparticles [20-35]. The aim of this research work is to synthesize silver nanoparticles from the aqueous flower extract of Musa acuminata.

Musa is one of two or three genera in the family Musaceae; it includes bananas and plantains. Around 70 species of Musa are known, with a broad variety of uses. Though they grow as high as trees, banana and plantain plants are not woody and their apparent "stem" is made up of the bases of the huge leafstalks. Thus, they are technically gigantic herbs. Musa species are used as food plants by the larvae of some Lepidoptera species. The banana fruits and flower are said to be composed of important phytochemicals such as cartenoids especially beta-carotene, lutein, malic acids, ascorbic acid, isopentyl acetate, esters of pentanol, butyric acid, eugenol, Omethyleugenol and elemicin [36]. These phytochemicals are employed in the reduction of silver ion $\left(\mathrm{Ag}^{+}\right)$and also serve as capping agent. In this work, we report the green synthesis of AgNPs using air dried Musa acuminata flower and evaluation of its antibacterial activities using some drug-resistant strains of bacteria.

\section{Materials and experimental methods}

Musa acuminate flowers were collected from a residence in Ajilosun area of Ekiti State, Nigeria. The flowers were peeled and air dried. The dried flowers were crushed using mortar and pestle, and thereafter pulverized using an electric blender. 


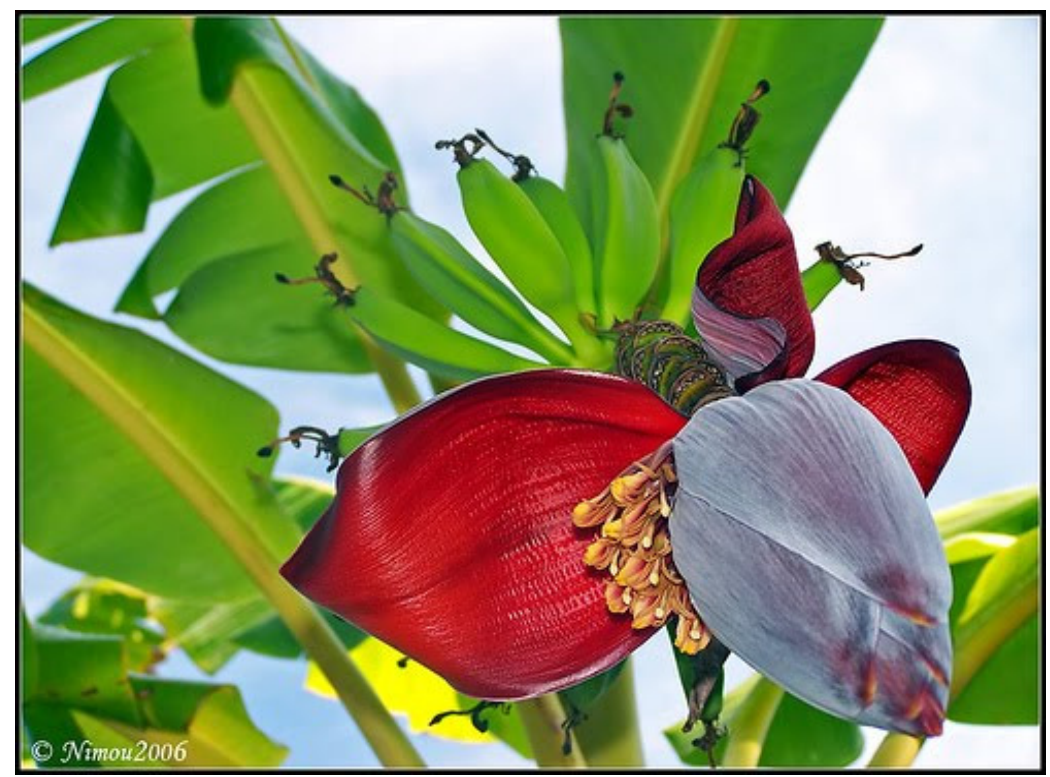

Figure 1: Musa acuminata with flowers

\subsection{Preparation of the aqueous Musa acuminata flower extract}

About $20 \mathrm{~g}$ of the powdered flower of Musa acuminata was weighed into $100 \mathrm{~mL}$ of distilled water in a $500 \mathrm{~mL}$ beaker and boiled on hot plate for 30 mins. The beakers were allowed to cool and filtered using a mesh net. The extracts were centrifuged using a centrifuge (800D, China) at $4000 \mathrm{rpm}$ for $20 \mathrm{~min}$. The supernatant was collected and used for the synthesis of the Ag nanoparticles.

\subsection{Biogenic synthesis of AgNPs}

The aqueous extract of the Musa acuminata flower was used to synthesize AgNPs. $10 \mathrm{~mL}$ of the extract was added to the reaction vessel containing $90 \mathrm{~mL}$ of $1 \mathrm{mM}$ silver nitrate $\left(\mathrm{AgNO}_{3}\right)$ solution for the reduction of silver ion $\left(\mathrm{Ag}^{+1}\right.$ to $\left.\mathrm{Ag}^{0}\right)$ according to this reaction :

$\mathrm{Ag}^{+}+\mathrm{e}^{-} \rightarrow \mathrm{Ag}^{0}$

The reaction was carried out in static condition at room temperature $\left(30 \pm 2^{\circ} \mathrm{C}\right)$ for $2 \mathrm{~h}$ [27].

\subsection{Characterization of the biosynthesized AgNPs}

The AgNPs was characterized using UV-Vis spectrophotometer, Fourier transform Infrared spectrophotometer (FTIR), Scanning Electron Microscope (SEM), Energy Dispersive X-ray (EDX)

2.3.1 UV-Vis spectrophotometer

The formation of AgNPs was monitored through visual observation of the change of colour and measurement of the maximum absorbance using UV-visible spectrophotometer model 6715 (Jenway Ltd. Essex, UK)

2.3.2 Fourier Transform Infrared Spectrophotometer

To give qualitative and preliminary analysis of the main functional groups that might be involved in nanoparticle synthesis, FT-IR analysis was performed on the AgNPs and concentrated Musa acuminata aqueous extract using Fourier Transform Infrared Spectrometer (Perkin Elmer Spectrum 100 series spectrometer, USA). This was conducted at the University of Ibadan, Department of Geology, Nigeria. Five milligramme (5 mg) of AgNPs and Musa acuminata aqueous extract were homogenously mixed separately with dry potassium bromide in a disc by applying pressure. The spectra of the AgNPs were measured within the range of $4000-400 \mathrm{~cm}^{-1}$ wave number.

2.3.3 Scanning Electron Microscope (SEM) and Energy Dispersive X-Ray Analysis (EDX)

The morphology of the AgNPs was examined. Sample was first gold coated using sputter coater, Edwards S150, which provides conductivity to the samples and then the SEMs spectra was taken. This technique allows SEM to examine the internal ultrastructure of thin AgNPs. The quantitative and qualitative elemental composition of the AgNPs was carried out in the Department of Geology, University of Ibadan, Nigeria using a Horiba Energy Dispersive X-ray Spectrometer coupled with X-ray microanalysis, transmitted electrons can be used for acquisition of elemental information and distribution

\subsection{Antimicrobial activities of synthesized AgNPs}

Silver nanoparticles exhibit promising applications in several biomedical fields such as biomedicine, drug delivery and antiangiogenics [37].The AgNPs was tested against two gram positive (S. aureus and B. subtilis) 
shown in Plates 1 below and two gram negative microbes (E. aerogenes and E. coli) shown in Plates 2 below to evaluate their antimicrobial activities.

\section{Results and discussion}

\subsection{Ultraviolet-Visible (UV-Vis) spectroscopic analysis}

The visual observation of the Musa acuminata extracts, silver nanoparticles (Figure 2) synthesized revealed colour change from light brown to dark brown for the Ag nanoparticles. The UV-Vis spectrum of the Ag nanoparticle shown in Figure 3 is the spectra of the stabilized AgNPs. The appearance of the color was due to the excitation of the surface plasmon vibrations. The maximum absorbance of the AgNPs obtained was $375 \mathrm{~nm}$ (figure 3) which falls within the range $320 \mathrm{~nm}-550 \mathrm{~nm}$ reported by [38]. The colour of the two solutions (light brown and dark brown) could be easily distinguished from the inset Figure 2.

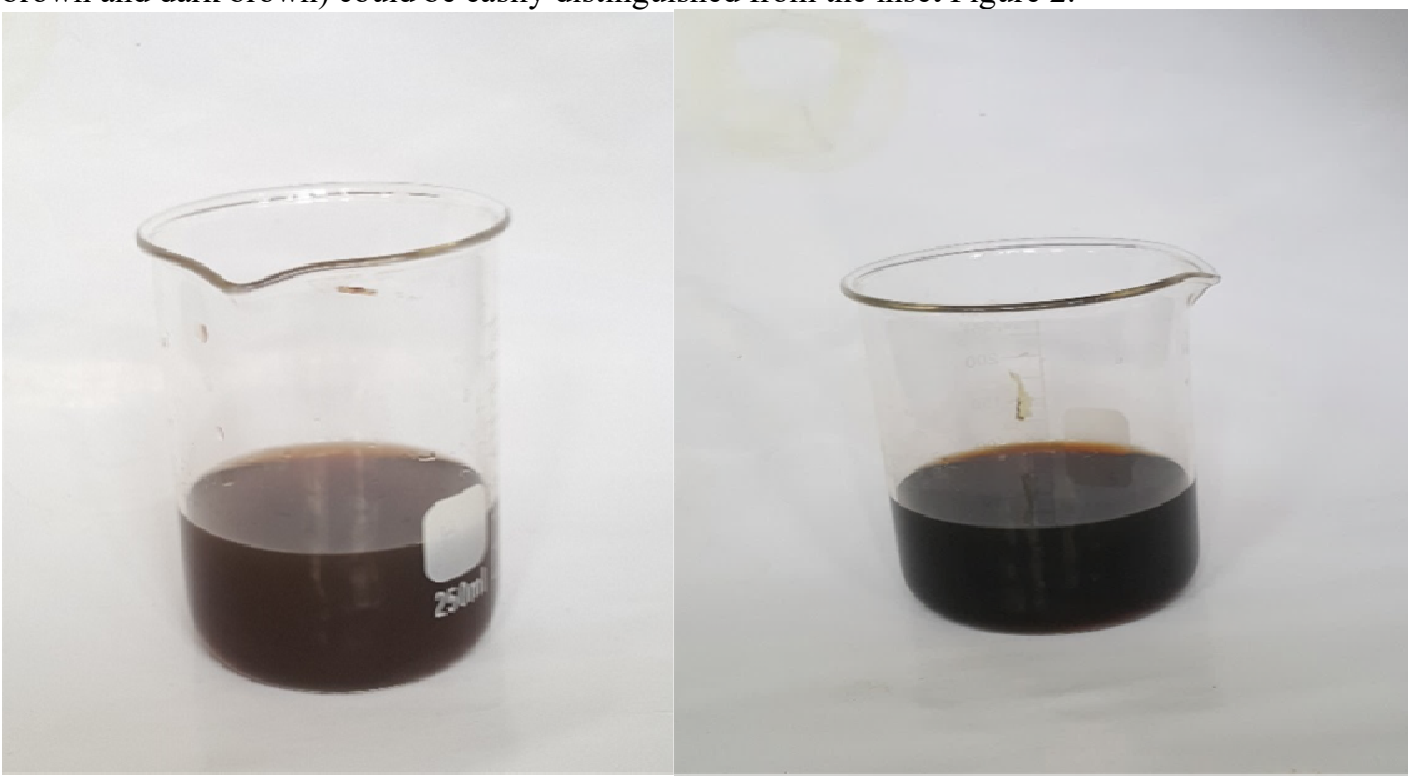

(a)

(b)

Figure 2.Musa acuminataflower extract (a) and Ag nanoparticles (b)

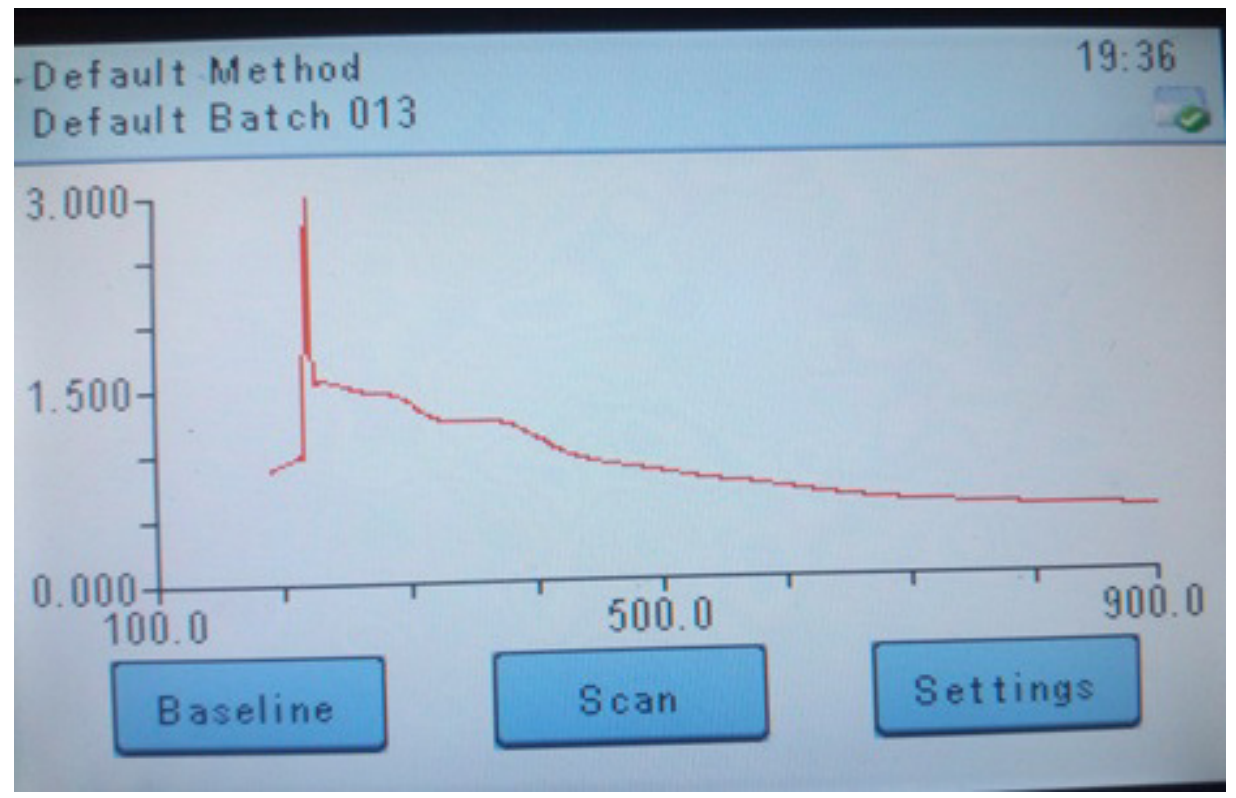

Figure 3. UV spectra of the AgNPs

\subsection{Fourier Transform Infrared Spectra (FTIR)}

The FTIR spectral in Figure 4 (H1) for the flower extract of Musa acuminata has band $3413 \mathrm{~cm}^{-1}$ assigned to $\mathrm{OH}$ stretching vibration bonded with Hydrogen, $1624 \mathrm{~cm}^{-1}$ is indicative of $\mathrm{N}-\mathrm{H}$ vibration of primary amine, $1383 \mathrm{~cm}^{-1}$ is associated with $-\mathrm{OH}$ bending vibration of phenol or tertiary alcohol / N-O stretching 
vibration and $1036 \mathrm{~cm}^{-1}$ shows the presence of $\mathrm{C}-\mathrm{N}$ stretching vibration of aromatic primary amine or $\mathrm{C}-\mathrm{O}$ stretching vibration of primary alcohol.

Figure $4(\mathrm{He} 1)$ revealed bands at $3420 \mathrm{~cm}^{-1}$ assigned to $-\mathrm{OH}$ stretching vibration bonded with Hydrogen, $2936 \mathrm{~cm}^{-1}$ which shows the presence of C-H stretching vibration of methylene group, $1651 \mathrm{~cm}^{-1} \mathrm{C}=\mathrm{O}$ of quinone, amide or conjugated ketone, $1384 \mathrm{~cm}^{-1}$ indicative of $-\mathrm{OH}$ bending vibrations, $1084 \mathrm{~cm}^{-1}$ suggested the presence of C-N stretching for primary amine, $467 \mathrm{~cm}^{-1}$ was assigned to $\mathrm{Ag}$.

The vibrational bands observed in the FTIR spectral in figure 4(H1) implied that the Musa acuminataextract is composed of amide, phenolic compounds which served as the reductant and stabilizing agents during the bionanosynthesis $[39,40]$. In figure $4(\mathrm{He} 1)$ the bands confirmed that the quinone, amide, phenolic compounds were present in the AgNP although had their bands reduced due to the stabilizing effect by chelation or electrostatic attraction [8].
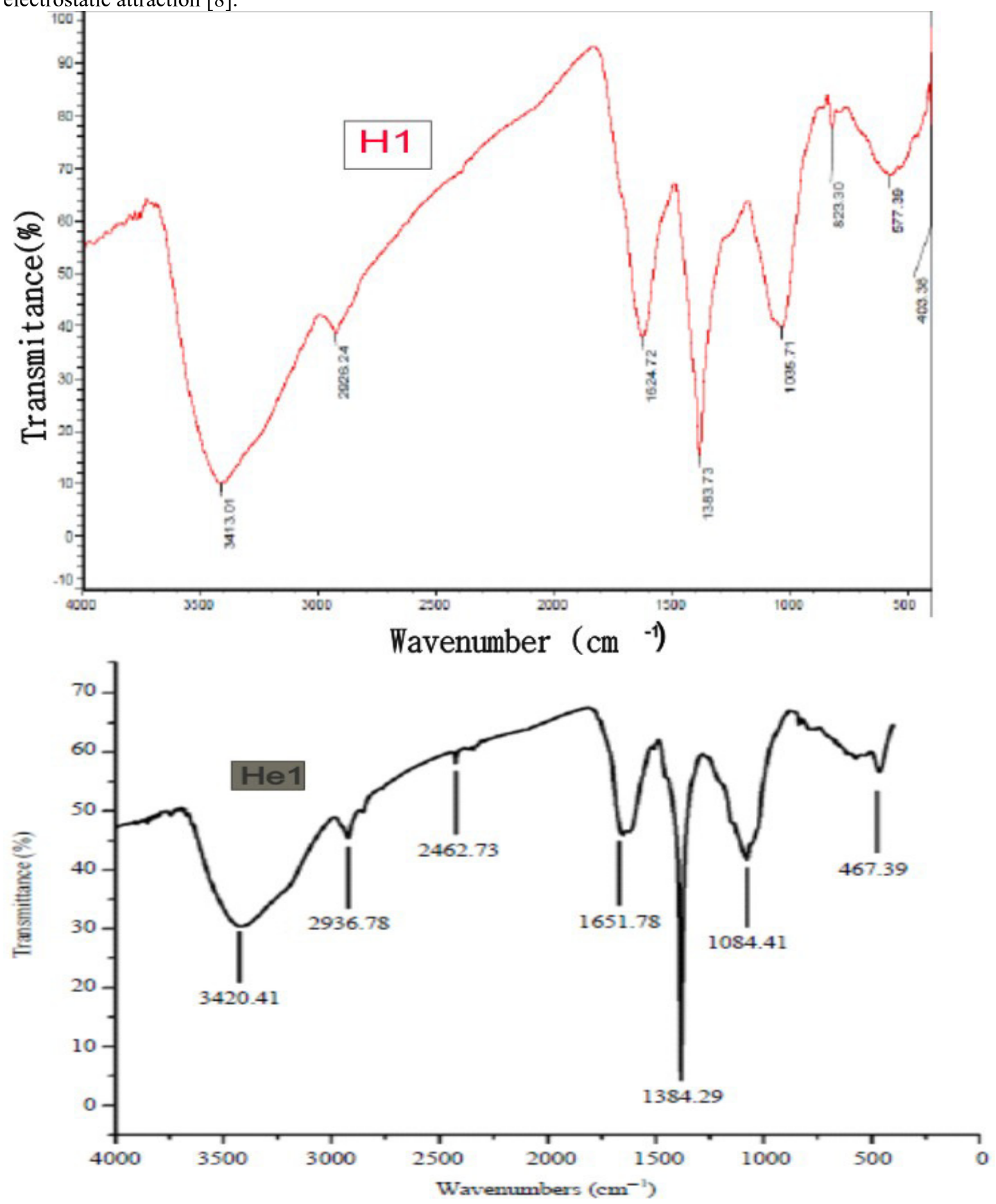

Figure 4. FTIR spectra for flower extract (H1) and the AgNPs (He1) 


\subsection{SEM and EDX Analysis}

The morphology of the silver nanoparticle (figure 5b) is completely different from the aqueous flower extract (figure 5a). The qualitative, as well as quantitative elemental profile was ascertained using EDX microanalysis. EDX spectral analysis demonstrated higher counts at $3 \mathrm{keV}$ due to silver confirming the development of silver nanoparticles, thus revealed the elemental composition of other elements present in the AgNP (Figure 6).

SEM image denote that the synthesized AgNPs were spherical in shape with varying sizes ranged between 20-30 nm. The EDX spectra revealed that Ag metal is the most abundant element in the AgNP which confirmed the formation of the nanoparticle.

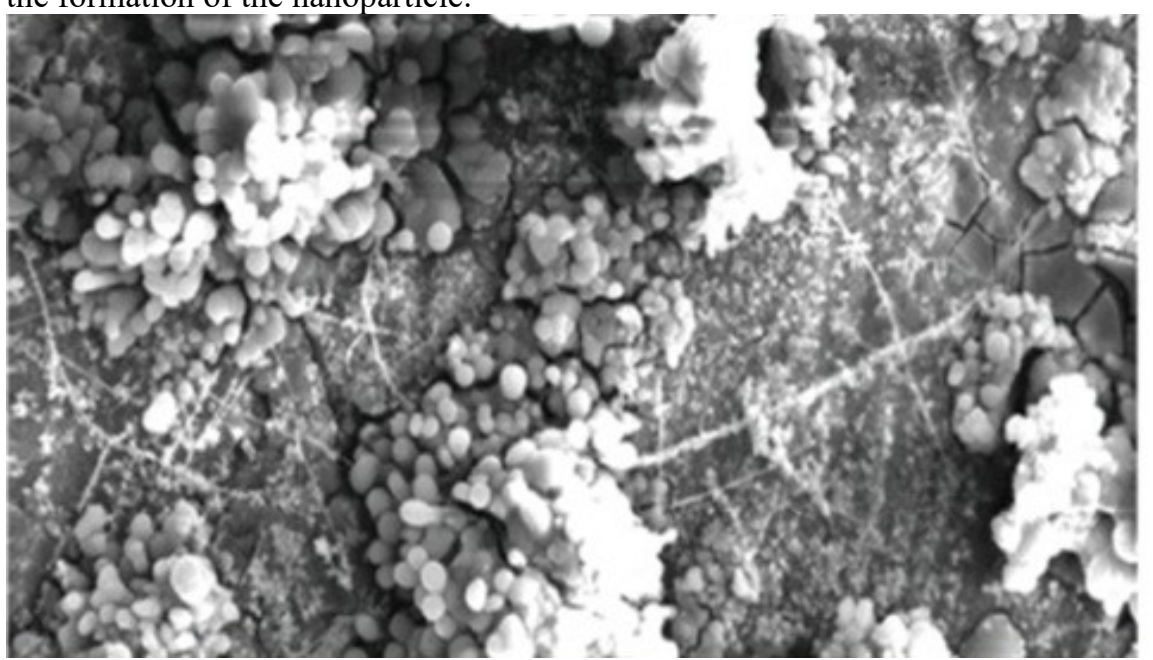

(a)

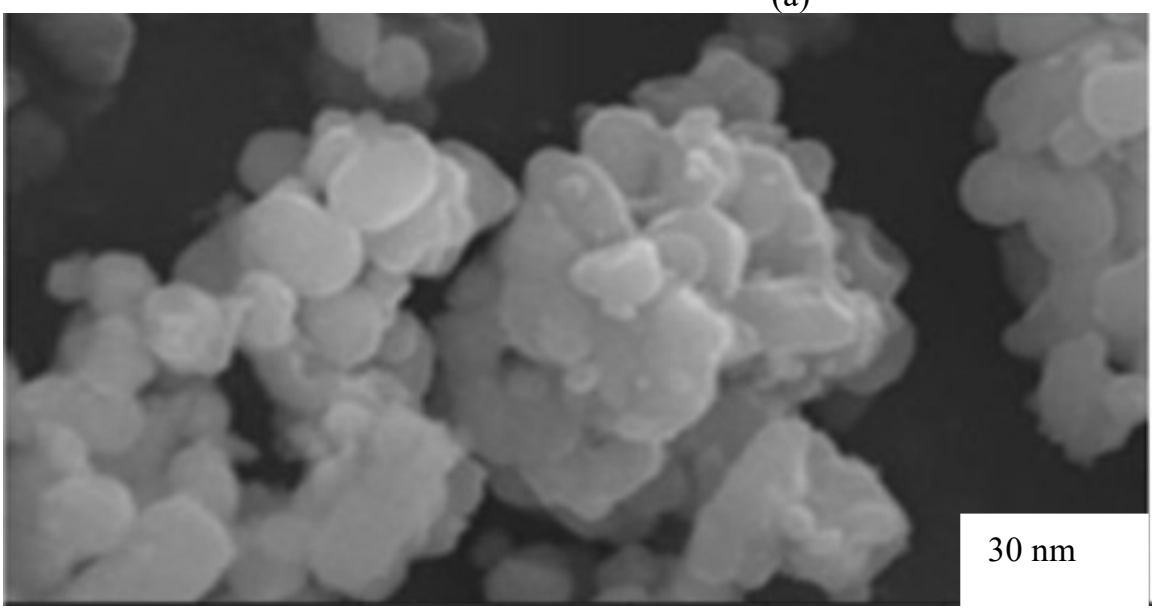

(b)

Figure 5. SEM micrographs of flower extract (a) and AgNP (b)

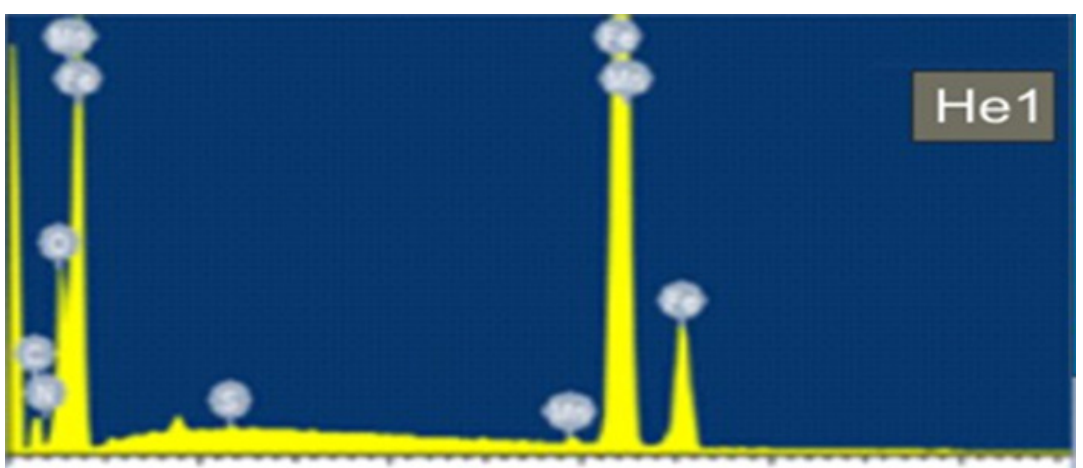

\begin{tabular}{|l|l|}
\hline Element & Wt \% \\
\hline $\mathrm{Ag}$ & 70.42 \\
\hline $\mathrm{Si}$ & 1.44 \\
\hline $\mathrm{C}$ & 30.68 \\
\hline $\mathrm{K}$ & 0.90 \\
\hline $\mathrm{O}$ & 9.12 \\
\hline
\end{tabular}

Figure 6. EDX spectra of AgNP (He1)

\subsection{Antibacterial activities of biosynthesized AgNPs}

The AgNPs was tested against two gram positive (S. aureus and B. subtilis) shown in Plates 1-2 below and two 
gram negative microbes (E. aerogenes and E. coli) shown in Plates 3-4 below to evaluate their antimicrobial activities.

The flower extracts AgNP inhibited E. aerogenes by $7.5 \mathrm{~mm}$. This implied that the AgNP possess antimicrobial activity after the nanosynthesis .E.coli was inhibited with the flower extract AgNP by $11 \mathrm{~mm}, S$. aureus showed inhibition to AgNPs by $3 \mathrm{~mm}$. B. subtilis showed a greater inhibition with AgNPs by $7.5 \mathrm{~mm}$. Table 1 below showed the size of inhibition of the AgNPs on each microorganisms used. Thus, it can be inferred that the AgNPs prepared have good antibacterial activity and employed as potent therapeutic agents at much smaller concentration. It has been reported that the changes observed in the membrane structure of bacterial cell wall due to the action of AgNPs was caused by the interaction of embedded silver nanoparticles resulting in increased membrane permeability and consequently, death of the bacteria [42]. Musa acuminata flower extract is capable for the green and eco-friendly synthesis of Ag nanoparticles which can be used as a potential entrant species having antibacterial applications.

Table 1: Antimicrobial activity of AgNPs against microorganisms

\begin{tabular}{ll}
\hline Microorganism & AgNPs \\
\hline E. aerogenes & $7.5 \mathrm{~mm}$ \\
E. coli & $11.0 \mathrm{~mm}$ \\
S. aureus & $3.0 \mathrm{~mm}$ \\
B. substilis & $7.5 \mathrm{~mm}$ \\
\hline
\end{tabular}

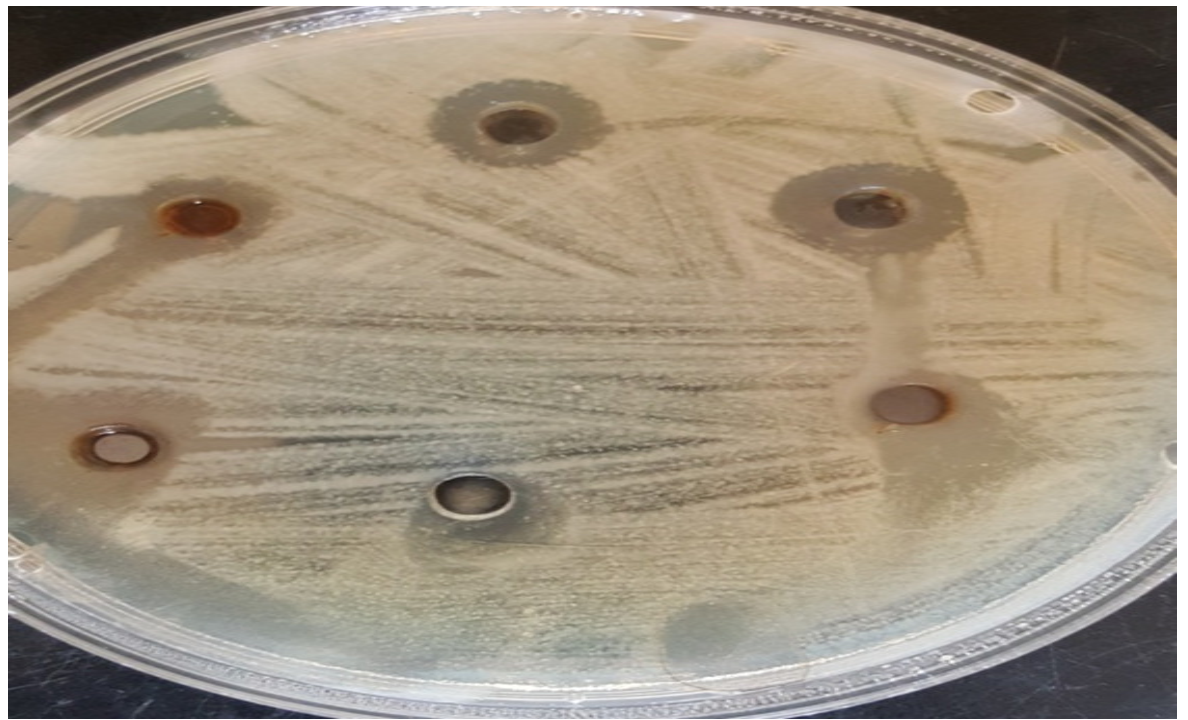

Plate 1: Inhibition of AgNPs on B. subtilis

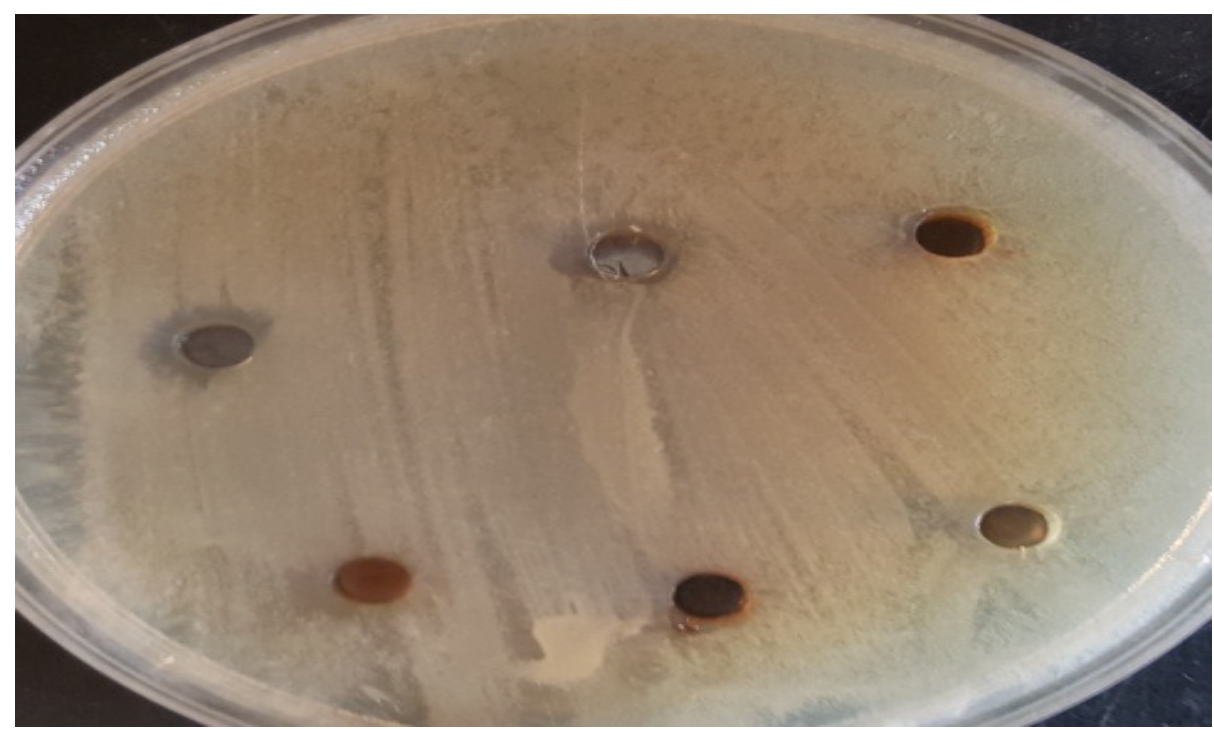

Plate 2: Inhibition of AgNPs (C) on S. aureus. 


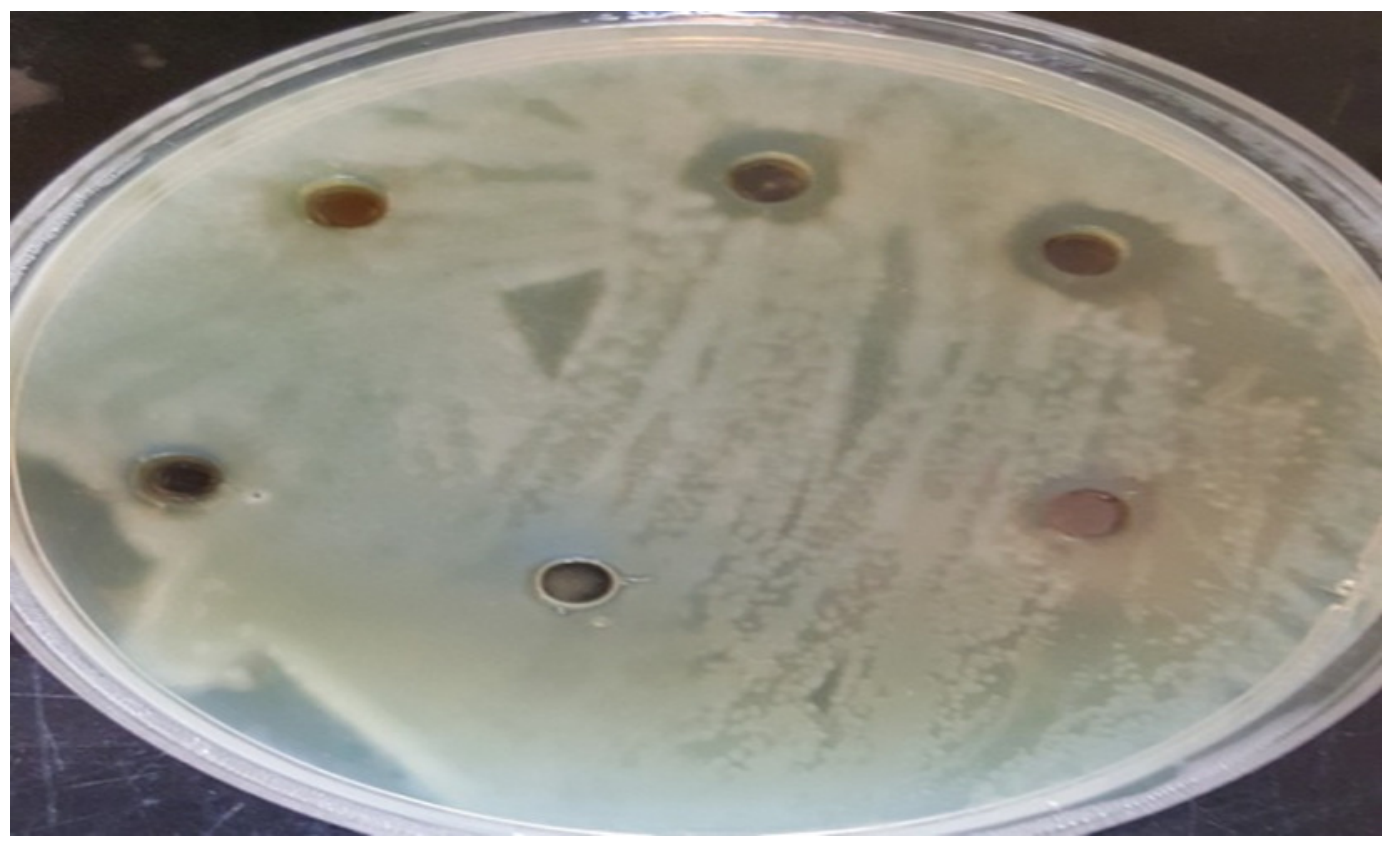

Plate 3: Inhibition of AgNPs on E. coli

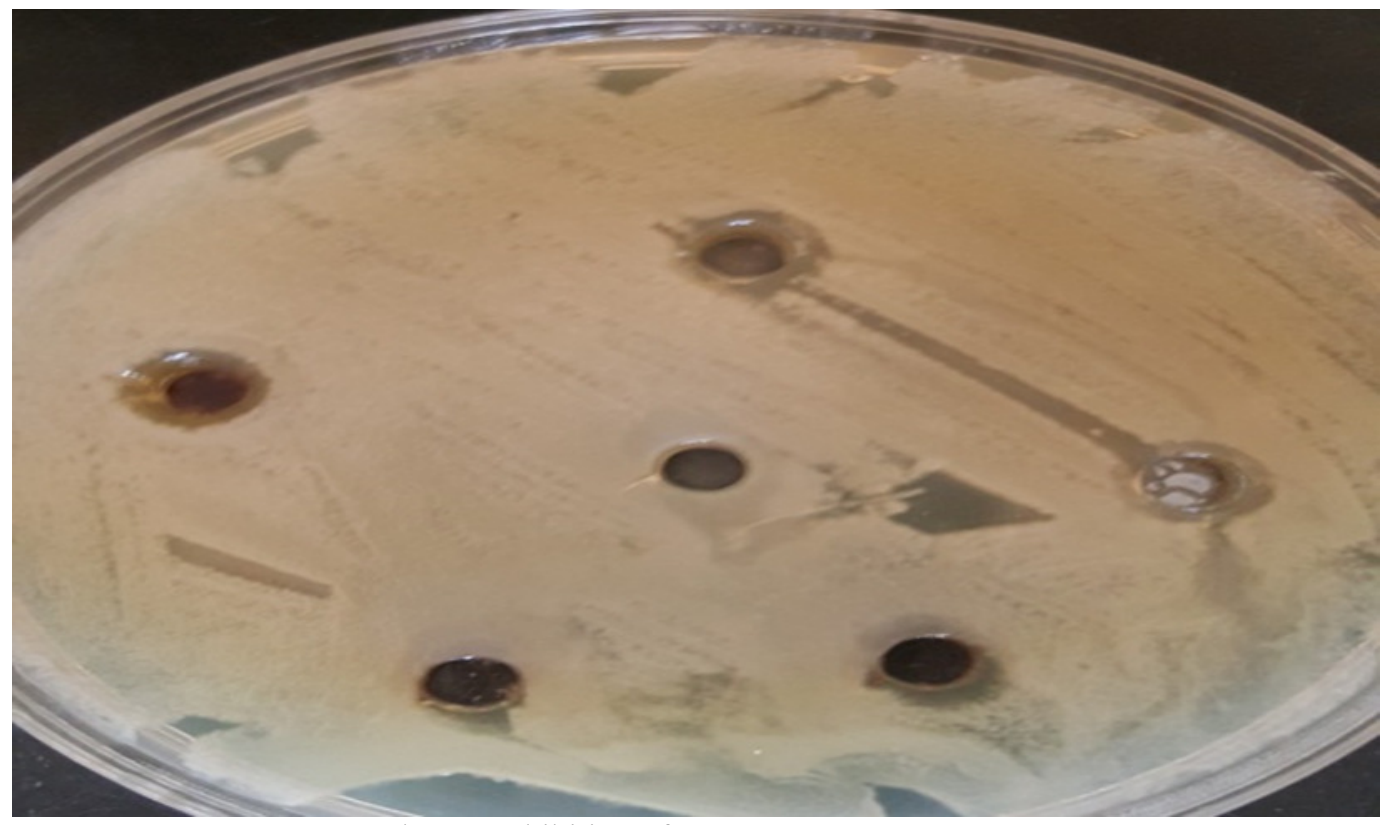

Plate 4: Inhibition of AgNPs on E. aerogenes

\section{Conclusions}

In this study, Musa acuminata mediated Ag nanoparticles were synthesized using flower extract. The synthesized AgNPs was analyzed using UVspectrophotometer, FTIR, SEM and EDX. The biosynthesized silver nanoparticles were proved to have excellent antibacterial performance against selected microbes. Therefore, Musa acuminata mediated Ag nanoparticles may be potentially utilized for the economic production of AgNPs for many pharmaceutical applications.

\section{Acknowledgements}

The authors express gratitude to MrsFadugba Bimbo of the Microbiology laboratory of AfeBabalola University, Ado-Ekiti for the technical support during the antimicrobial screening of the synthesized silver nanoparticles.

\section{Disclosure statement}

No potential conflict of interest was reported by the author. 


\section{References}

[1] Shalini C.; Pragnesh N.; Dave N.; Shah K. Applications of nano-catalyst in new era. Journal of Saudi Chemical Society 2012, 16, 307-325.

[2] Singh H.; Santosh K.; and Tandon P. Catalysis: A brief review on Nano-Catalyst. Journal of Energy and Chemical Engineering (JECE) 2014, 2,106-115.

[3] Nikalje A. Nanotechnology and its Applications in Medicine. Med chem 2015, 5, 081-089, Doi:10.4172/2161-0444.1000247

[4] Santhi M.; Kumar P.E.; and Muralidharan B. Removal of Malachite Green Dyes By Adsorption onto Activated Carbon $-\mathrm{MnO}_{2}-$ Nanocomposite - Kinetic Study and Equilibrium Isotherm Analyses. IOSR Journal of Applied Chemistry 2015, 8(4), 33-41, DOI: 10.9790/5736-08413341.

[5] Jayasantha H.; Kumari P.; Arumugam T.; Radhakrishnan S.; Vasudevan D. An efficient removal of crystal violet dye from waste water by adsorption onto TLAC/Chitosan composite: A novel low cost adsorbent. International Journal of Biological Macromolecules 2014, 6,118-128, http://dx.doi.org/10.1016/j.ijbiomac.2016.11.077

[6] Mansoureh Z.; Majid K.; Zahra K.; Khoramdareh M. Removal of Methylene Blue Using Polyacrylic Acid/Octavinyl Polyhedral OligomericSilsesquioxaneNanocomposite. J. Nanoanalysis 2017, 4(2), 134-141.

[7] Wang L.; and Wang A. Adsorption characteristics of Congo Red onto the chitosan/montmorillonitenanocomposite. Journal of Hazardous Materials 2007,147, 979-985.

[8] Olajire A.; Abidemi J.; Lateef A.; and Benson N. Adsorptive desulphurization of model oil by Ag nanoparticles modified activated carbon prepared from brewers spent grains. Journal of environmental chemical engineering 2017, 5,147-159.

[9] Olajire A.; Olanrewaju S.; andLawal W. Silver Nanoparticle-Assisted Adsorptive Desulfurizationby Composted Agro-Waste Activated Carbons.Int J Environ Res 2017, 11,263-279,DOI 10.1007/s41742-0170025-3

[10] Abdel-Raouf N.; Alharbi R.; Al-Enazi N.; Alkhulaifi M.; Ibraheem S. Rapid Biosynthesis of Silver Nanoparticles Using the marine red alga Laurenciacatarinensis and their characterization. Beni-Suef University Journal of Basic and Applied Sciences 2017, 6, 345-355, Doi: https://doi.org/10.1016/j.bjbas.2017.10.003

[11] Ibraheem M.; Hamed S.; Abdel-Rhman A.; Farag M.; Abdel-Raouf N. Antimicrobial activities of some brown macroalgae against some soil borne plant pathogens and in vivo management of Solanummelongena root diseases. Aust. J. Basic \& Appl. Sci2017,11(5),157-168.

[12] Jeyaraj M.; Sathishkumar G.; Sivanandhan G.; MubarakAli D.; Rajesh M.; Arun R.; Kapildev M.; Manickavasagam N.; Thajuddin K.; Premkumar A.; Ganapathi D. Biogenic silver nanoparticles for cancer treatment: An experimental report. Colloids and Surf B:Biointerfaces 2013, 10, 686-92.

[13] Okafor F.; Janen A.; Kukhtareva T.; Edwards V.; Curley M. Green synthesis of silver nanoparticles, their characterization, application and antibacterial activity. Int. J. Environ.Res. Public Health 2013, 10, 52215238

[14] Benakashani F.; Allafchian A.; Jalali S. Biosynthesis of silver nanoparticles using Capparisspinosa L. leaf extract and their antibacterial activity. Karbala International Journal of Modern Science 2016, 231-242, http://dx.doi.org/10.1016/j.kijoms.2016.08.004

[15] Navaladian S.; Viswanathan B.; Viswanath R.; Varadarajan T. Thermal decomposition as route for silver nanoparticles.Nanoscale Res. Lett. 2007,2 (1), 44-48.

[16] Starowicz M.; Stypuła B.; Banas J. Electrochemical synthesis of silvernanoparticles. Electrochem.Commun 2006, 8 (2), 227-230.

[17] Sreeram K.; Nidhin M.; Nair B. Microwave assisted template synthesis of silver nanoparticles. Bull. Mater. Sci. 2008,31 (7), 937-942.

[18] Begum N.; Mondal S.; Basu S.; Laskar R.; Mandal D. Biogenic synthesis of Au and Ag nanoparticles using aqueous solutions of Black Tea leaf extracts. Colloids Surfaces B Biointerfaces 2009,71 (1), 113-118

[19] Lateef A.; Adelere I.A.; Gueguim-Kana E.B.; Asafa T.B.; Beukes L.S. Green synthesis of silver nanoparticles using keratinase obtained from a strain of Bacillus safensis LAU 13. Int. Nano Lett.2015, 5, 29-35.

[20] Aromal S.; Philip D. Green synthesis of gold nanoparticles using Trigonellafoenum-graecum and its size dependent catalytic activity. SpectrochimicaActa2012, 97, 1-5.

[21] Kasthuri J.; Veerapandian S.; Rajendiran N. Biological synthesis of silver and gold nanoparticles using apiin as reducing agent. Colloids and Surfaces BBiointerfaces2009,68, 55-60.

[22] Mahdavi M.; Namvar F.; Ahmad M.B.; Mohamad R. Green biosynthesis and characterization of magnetic iron oxide (Fe3O4) nanoparticles using seaweed (Sargassummuticum) aqueous extract. Molecules 2013, 18, 5954-5964. 
[23] Gopinath V.; MubarakAli D.; Priyadarshini S.; Meera N.; Priyadharsshini N.; Thajuddin N.; Velusamy P. Biosynthesis of silver nanoparticles from Tribulusterrestris and its antimicrobial activity: A novel biological approach. Colloid and Surf B: Biointerfaces 2012,96, 69-74.

[24] Shanmuganathan R.; MubarakAli D.; Prabakar D.; Muthukumar H.; Thajuddin N.; Smita S.; Pugazhendhi A. An enhancement of antimicrobial efficacy of biogenic and ceftriaxone-conjugated silver nanoparticles: green approach. Environ. Sci. Pollu. Res. 2014, 10, 9367-9,DOI: 10.1007/s11356-017-9367-9.

[25] Lateef A.; Ojo S.A.; Azeez M.A.; Asafa T.B.; Yekeen T.A.; Akinboro A.; Oladipo I.C.; Gueguim-Kana E.B.; Beukes L.S. Cobweb as novel biomaterial for the green and eco-friendly synthesis of silver nanoparticles. Appl. Nanosci. 2015, 10, 492-9,http://dx.doi.org.10.1007/s13204-015-0492-9.

[26[ Nazeruddin G.M.; Prasad N.R.; Prasad S.R.; Shaikh Y.I.; Waghmare S.R.; Adhyapak P. Coriandrumsativum seed extract assisted in situ green synthesis of silver nanoparticle and its anti-microbial activity.Ind. Crops Prod. 2014, 60,212-216

[27] Lateef A.; Azeez M.A.; Asafa T.A.; Yekeen T.A.; Akinboro A.; Oladipo I.C.; Ajetomobi F.E.; GueguimKana E.B.; Beukes L.S. Cola nitida-mediated biogenic synthesis of silver nanoparticles using seed and seed shell extracts and evaluation of antibacterial activities. BioNanoSci.2015b, 10, 181-190, http://dx.doi.org.10.1007/s12668-015-0181-x.

[28] Edison T.J.I.; Sethuraman M.G. Instant green synthesis of silver nanoparticles using Terminaliachebula fruit extract and evaluation of their catalytic activity on reduction of methylene blue. Process Biochem. 2012, 47,1351-1357

[29] Ahmad N.; Sharma S.; Alam K.; Singh V.N.; Shamsi S.F.; Mehta B.R.; Fatma A. Rapid synthesis of silver nanoparticles using dried medicinal plant of basil. Colloids Surf. B Biointerfaces 2010, 81, 81-86.

[30] Mollick M.R.; Bhowmick B.; Maity D.; Mondal D.; Roy I.; Sarkar J.; Rana D.; Acharya K.; Chattopadhyay S.; Chattopadhyay D. Green synthesis of silver nanoparticles-based nanofluids and investigation of their antimicrobial activities.Microfluid.Nanofluid. 2014,16, 541-551.

[31] Singh A.; Jain D.; Upadhyay M.K.; Khandelwal N.; and Verma H.N. Green synthesis of silver nanoparticles using Argemonemexicana leaf extract and evaluation of their antimicrobial activities. Dig. J. Nanomater. Biostruct. 2010, 5, 483-489.

[32] Gurunathan S.; Jeong J.K.; Han J.W.; Zhang X.F.; Park J.H.; Kim J.H. Multidimensional effects of biologically synthesized silver nanoparticles in Helicobacter pylori, Helicobacter felis, and human lung (L132) and lung carcinoma A549 cells. Nanoscalen Res. Lett. 2015, 10, 1-17.

[33] Muniyappan N.; Nagarajan N.S. Green synthesis of silver nanoparticles with Dalbergiaspinosa leaves and their applications in biological and catalytic activities. Process Biochem.2014,49,1054-1061

[34] Fayaz A.M.; Balaji K.; Girilal M.; Yadav R.; Kalaichelvam P.T.; Venketesan R. Biogenic synthesis of silver nanoparticles and their synergistic effect with antibiotics: a study against gram-positive and gram-negative bacteria.Nanomedicine: Nanotech. Biol. Med. 2010,6, 103-109.

[35] Niraimathi K.L.; Sudha V.; Lavanya R.; Brindha P. Biosynthesis of silver nanoparticles using Alternantherasessilis (Linn.) extract and their antimicrobial, antioxidant activities. Colloids Surf. B: Biointerf. 2013,102, 288-291.

[36] Idachaba M.; and Onyezili F. Physical, chemical and microbiological considerations in processing plantain (Musa paradisiaca L.) into 'Medi', a Nigerian food drink. Sciences des Aliments 1994,14(2), 229-234.

[37] Reddy N.J.; Nagoor V. D.; Rani M.; Sudha R.S. Evaluation of antioxidant, antibacterial and cytotoxic effects of green synthesized silver nanoparticles by Piper longum fruit.Mater.Sci. Eng. 2014, 34, 115-122.

[38] Thirumurugan A.; Tomy N.A; Kumar H.P; Prakash P. Biological synthesis of silver nanoparticles by Lantana camara leaf extracts. Int J NanomaterBioresource 2011,1,22-24

[39] Kalsi P.S. Spectroscopy of organic compounds. 6th ed. New Delhi: new age int, 2007

[40] Coates J. Practical approach to interpretation of infrared spectra. John wiley and sons Ltd, chicester2000, 10815-10837.

[41] Pavia L.D.; Gary M.L. and George S.K. Introduction to Spectroscopy. $3^{\text {rd }}$ ed.Thomson learning, 2001.

[42] Dibrov P.; Dzioba J.; Gosink K.K.; Hase C.C. Chemiosmotic mechanism of antimicrobial activity of $\mathrm{Ag}(+)$ in Vibrio cholera.Antimicrob.Agents Chemother. 2002, 46, 2668-2670. 